\title{
Talking about firearm injury prevention with patients: a survey of medical residents
}

\author{
Rocco Pallin ${ }^{1,2,3^{*}}$, Sara Teasdale ${ }^{4}$, Alicia Agnoli5 ${ }^{5}$, Sarabeth Spitzer ${ }^{6}$, Rameesha Asif-Sattar ${ }^{1,2}$, \\ Garen J. Wintemute ${ }^{1,2}$ and Amy Barnhorst ${ }^{2,7}$
}

\begin{abstract}
Background: Firearm injury and death are significant public health problems in the U.S. and physicians are uniquely situated to help prevent them. However, there is little formal training in medical education on identifying risk for firearm injury and discussing safe firearm practices with patients. This study assesses prior education, barriers to counseling, and needs for improved training on firearm safety counseling in medical education to inform the development of future education on clinical strategies for firearm injury prevention.
\end{abstract}

Method: A 2018 survey administered to 218 residents and fellows at a large, academic medical center asked about medical training on firearm injury prevention, frequency of asking patients about firearm access, and perceived barriers.

Results: The most common barriers cited were not knowing what to do with patients' answers about access to firearms (72.1\%), not having enough time (66.2\%), not feeling comfortable identifying patients at risk for firearm injury (49.2\%), and not knowing how to ask patients about firearm access (48.6\%). Prior education on firearm injury prevention was more strongly associated with asking than was personal exposure to firearms: $51.5 \%$ of respondents who had prior medical education reported asking compared with who had not received such education $(31.8 \%, p=0.004)$. More than $90 \%$ of respondents were interested in further education about interventions, what questions to ask, and legal mechanisms to separate dangerous people from their firearms.

Conclusions: Education on assessing risk for firearm-related harm and, when indicated, counseling on safe firearm practices may increase the likelihood clinicians practice this behavior, though additional barriers exist.

Keywords: Medical education, Firearm injury prevention, Patient counseling, Medical interns, Medical training, Firearm violence, Safe fiream storage

\section{Background}

Firearm injury and death are significant public health problems in the United States, and physicians occupy a unique position to address it. In 2019, 39,704 people died by firearms, nearly two-thirds of them from firearm suicides [1]. Firearms are readily accessible to many; an

\footnotetext{
*Correspondence: rspallin@berkeley.edu

${ }^{3}$ Department of Emergency Medicine, University of California, Davis, 2315 Stockton Blvd, Sacramento, CA 95817, USA

Full list of author information is available at the end of the article
}

estimated 35\% of American adults live in a household with a firearm, and in a majority of those households firearms are not stored in the most secure manner [2, 3]. A substantial body of evidence has found that firearms in the home increase the risk of firearm suicide, homicide, and unintentional injury for those living there, and that safe firearm storage reduces the risk of firearm-related harm [4-10]. By knowing how to identify risk for firearm-related harm, knowing possible steps to reduce access by at-risk persons, and talking with patients, parents, or caregivers about the danger of access to firearms 
in the home when someone is at increased risk, clinicians can help prevent firearm injury and death [11].

Despite this, many clinicians do not routinely ask about access to firearms in their practice, even when such screening is clinically indicated [12,13]. One study of emergency department patients with suicidal ideation or attempt found that $55 \%$ of the patients discharged home had no documentation of a lethal means assessment, and $13 \%$ of those patients later told researchers they had at least 1 firearm at home at the time [14]. In a survey of practicing psychiatrists, only $27 \%$ of respondents said they routinely asked their patients about firearm safety, although most believed that their patients were at higher risk of adverse events involving firearms [15]. A survey of family practice physicians and pediatricians found that, despite believing they had a responsibility to do so, very few counselled patients about safe firearm practices [16].

Physicians cite lack of knowledge as a primary barrier to firearm counseling in a clinical setting [12]. Groups such as the American College of Physicians [17], California Medical Association [18], and American Academy of Pediatrics [19] support physician screening for firearm violence prevention, and research suggests that 65 to 93 percent of physicians recognize firearm counseling as within a physician's scope of practice [20]. Physicians may need education and training on firearm injury prevention in order to incorporate it into their practices. To our knowledge, few medical schools and residency training programs include substantial formal training on discussing firearms with patients in their core curriculum.

A 2016 review of the literature on firearm safety curricula in medical education found only two reports evaluating programs teaching medical students or residents [21]. Two articles in Academic Psychiatry in 2010 called for better training on anticipatory guidance related to firearms in psychiatric residency [22,23], but five years later, a literature review found no such training directed at psychiatrists or psychiatry residents [21]. In the 1990s, only one third of pediatric residency programs nationwide offered any firearm safety counseling training, and only 16 percent of family practice residencies offer such training $[24,25]$. Given that practitioners who had received information about firearm safety were more likely to have such discussions with their patients [15], it has been suggested that the development of firearm safety education programs for physicians be made a priority [21].

To examine specific needs for improved training, we conducted a survey to assess to what degree and by what methods medical trainees at a major academic medical center are taught about firearm injury prevention, and to what extent they are implementing that knowledge in their clinical practice. The survey also explored whether trainees are having these discussions with patients, why they are not, and what they would like to be taught on this topic.

\section{Methods \\ Study population}

During a two-week period in March and April of 2018, we distributed an electronic survey via email to all 759 residents and fellows at a large, urban, university-based academic medical center.

\section{Survey instrument}

We developed a 12-question anonymous survey. We performed a literature review, created a question bank, and, where possible, adopted questions used in prior surveys on firearm injury prevention in medical education. The survey questions addressed what trainees had been taught about firearms thus far in their medical education, if they asked about firearm access in clinical practice, what had been their personal experience with firearms, and their interest in firearm injury education, as well as basic demographic information. Using a 5-point scale, residents answered questions assessing frequency of screening for firearm injury prevention, exposure to firearms over their lifetimes, and interest in education programs designed to increase knowledge. The survey instrument was not validated. The full survey instrument is available in Additional file 1.

\section{Data collection}

The graduate medical education office electronically distributed the link to the survey, along with a cover letter explaining the purpose of the study, to all residents and fellows twice over a 2-week period.

We administered the survey online using Qualtrics. All participants were provided an informed consent statement, including that their participation was voluntary and responses anonymous, before beginning the survey. Survey initiation constituted consent.

\section{Data analysis}

We conducted bivariate analyses using the $\chi^{2}$ test for significance and used logistic regression to calculate odds ratios with 95\% confidence intervals. When cell sizes were small $(n<5)$, Fisher's exact tests were used to obtain p values. All analyses were conducted using Stata SE 15.1 for Mac (StataCorp, College Station, Texas).

We combined respondent specialties for analysis to yield five aggregate specialty groups: primary care, surgery, emergency, psychiatry, and other. The primary care group included respondents from family medicine, pediatrics, internal medicine, and the psychiatry/family medicine joint program to reflect the Association of American Medical Colleges designation, as well as obstetrics and 
gynecology. We collapsed responses to Likert or 5-point scale questions for analysis.

We classified all respondents as having either no or some lifetime firearm exposure based on their responses to questions on topics such as involvement in firearm safety courses, current or past firearm ownership, and exposure to firearms in the military.

The University of California at Davis Institutional Review Board deemed that this study did not constitute research and waived the need for ethics approval. All data collection and analyses were carried out in accordance with relevant reporting guidelines and regulations.

\section{Results}

Of the 759 residents and fellows who received the survey link, $218(28.7 \%)$ completed the survey. Most respondents $(83.9 \%)$ were residents, $54.6 \%$ were female, $85.8 \%$ were between the ages of 25 and 34, and $50.7 \%$ were in primary care (Table 1 ).

Nearly half of respondents (47.5\%) reported at least one lifetime exposure to firearms, including $30.6 \%$ who grew up in homes with firearms. More than half (60.0\%) reported having had education on firearms during their medical training (Table 1). See Additional file 2 for definition of collapsed variable categories.

Respondents with lifetime firearm exposure more often reported asking (49.0\%), compared with those having no lifetime firearm exposure $(39.1 \%, p=0.140)$. Those whose medical education included the topic of firearms more often reported asking (51.5\%) compared with those whose education had not covered firearms (31.8\%, $p=0.004)$. However, the groups were equally interested in future education on firearms (70.4 and $73.9 \%$, respectively) (Table 2).

Reported frequency of asking patients about firearms varied by specialty. Majorities of psychiatry $(90.0 \%)$ and emergency medicine (54.2\%) respondents reported ever asking (Table 2). Fewer than half of primary care (45.2\%), surgery (24.2\%), and other (4.2\%) respondents reported ever asking $(p=0.000)$. Relative to respondents in primary care, those in psychiatry were more likely to ask patients about firearms (OR: 10.9, CI: 2.4-49.5); those in surgery (OR: 0.4, CI: 0.2-0.9) and other specialties (OR: 0.1, CI: $0.0-0.4$ ) were less so (Table 3 ). Differences by specialty in having had firearm injury prevention covered in medical education and in interest in firearm injury prevention education were generally not statistically significant.

We asked respondents about their primary firearm access-related concern for their patients: suicide, homicide, or accidents. Respondents in primary care (46.6\%), emergency medicine (62.5\%), and psychiatry (85.0\%) reported being most concerned about suicide, while a majority of those in surgery $(54.6 \%)$ reported homicide
Table 1 Description of survey respondents $(n=218)$

\begin{tabular}{|c|c|c|}
\hline & Count & Percent \\
\hline TOTAL & 225 & - \\
\hline \multicolumn{3}{|l|}{ Level of training } \\
\hline Resident & 183 & 83.9 \\
\hline Fellow & 35 & 16.1 \\
\hline \multicolumn{3}{|l|}{ Gender } \\
\hline Male & 98 & 45.0 \\
\hline Female & 119 & 54.6 \\
\hline Other/Prefer not to say & 1 & 0.5 \\
\hline \multicolumn{3}{|l|}{ Age } \\
\hline $25-34$ & 188 & 85.8 \\
\hline $35-44$ & 26 & 11.9 \\
\hline $45-54$ & 5 & 2.3 \\
\hline \multicolumn{3}{|l|}{ Specialty category } \\
\hline Primary Care $^{a}$ & 104 & 50.7 \\
\hline Surgery & 33 & 16.1 \\
\hline Emergency & 24 & 11.7 \\
\hline Psychiatry & 20 & 9.8 \\
\hline Other & 24 & 16.1 \\
\hline \multicolumn{3}{|l|}{ Exposure to guns } \\
\hline Some lifetime exposure to firearms ${ }^{b}$ & 104 & 47.5 \\
\hline Took a safety course & 49 & 22.4 \\
\hline Owns a firearm & 30 & 13.7 \\
\hline Used a firearm in the military & 9 & 4.1 \\
\hline Lives in a gun household & 16 & 7.3 \\
\hline Grew up in a house with guns & 67 & 30.6 \\
\hline Fired a gun in the last year & 44 & 20.1 \\
\hline \multicolumn{3}{|l|}{ Some lifetime exposure to guns by gender } \\
\hline Male & 56 & 57.1 \\
\hline Female & 47 & 39.5 \\
\hline Had education on firearms in medical education & 132 & 60.0 \\
\hline \multicolumn{3}{|l|}{ State attended high school } \\
\hline California & 116 & 53.5 \\
\hline Other state & 90 & 41.5 \\
\hline International & 11 & 5.1 \\
\hline
\end{tabular}

a Primary care specialty includes respondents from family medicine, pediatrics, obstetrics and gynecology, and internal medicine. If respondents were in psychiatry/primary care joint program, they were included in the primary care group for these analyses

${ }^{\mathrm{b}}$ Excluding training in medical education. See Additional file 2 for definition of lifetime exposure to firearms

as their greatest concern. Compared to those in primary care, pyschiatrists were significantly more likely to report suicide as their major concern (OR: 6.5, CI: 1.9-23.5) and surgeons were significantly more likely to report homicide as their major concern (OR: 9.1, CI: 3.7-22.7).

The most common barriers to asking patients about firearms that respondents cited were not knowing what to do with patients' answers (72.1\%), not having enough time (66.2\%), not feeling comfortable identifying patients 
Table 2 Frequency of and barriers to asking about firearms by firearm exposure and by prior firearm education (percent)

\begin{tabular}{|c|c|c|c|c|}
\hline & \multicolumn{2}{|c|}{$\begin{array}{l}\text { Lifetime } \\
\text { exposure } \\
\text { to firearms } \\
\text { (\% of } \\
\text { respondents) }\end{array}$} & \multicolumn{2}{|c|}{$\begin{array}{l}\text { Firearm } \\
\text { education } \\
\text { in medical } \\
\text { training ( } \% \text { of } \\
\text { respondents) }\end{array}$} \\
\hline & Yes & No & Yes & No \\
\hline \multicolumn{5}{|l|}{ Frequency of asking patients about firearms } \\
\hline Never & 51.0 & 60.9 & 48.5 & $68.2^{\mathrm{a}}$ \\
\hline At least sometimes & 49.0 & 39.1 & $51.5^{\mathrm{a}}$ & $31.8^{\mathrm{a}}$ \\
\hline \multicolumn{5}{|l|}{ Reasons for not asking about firearms ${ }^{\mathrm{b}}$} \\
\hline Not enough time & 59.5 & 70.9 & 64.3 & 68.4 \\
\hline Afraid to offend patient & $22.4^{\mathrm{a}}$ & $40.2^{\mathrm{a}}$ & $24.7^{\mathrm{a}}$ & $43.3^{\mathrm{a}}$ \\
\hline Don't know if asking is legal & $6.4^{\mathrm{a}}$ & $24.6^{\mathrm{a}}$ & $6.9^{\mathrm{a}}$ & $27.5^{\mathrm{a}}$ \\
\hline $\begin{array}{l}\text { Nothing I can do if there is a gun in } \\
\text { the home }\end{array}$ & 30.0 & 24.7 & 28.2 & 27.0 \\
\hline Topic isn't clinically relevant & $28.3^{\mathrm{a}}$ & $6.9^{\mathrm{a}}$ & 14.8 & 21.6 \\
\hline $\begin{array}{l}\text { Firearms aren't within scope of } \\
\text { practice }\end{array}$ & 46.7 & 43.1 & $36.6^{\mathrm{a}}$ & $54.8^{\mathrm{a}}$ \\
\hline I don't know how to ID risk & 42.9 & 54.3 & 45.7 & 52.6 \\
\hline I don't know how to ask & 45.9 & 50.7 & $35.4^{\mathrm{a}}$ & $65.5^{\mathrm{a}}$ \\
\hline I don't know what to do with answers & 75.7 & 70.2 & $64.6^{\mathrm{a}}$ & $82.2^{\mathrm{a}}$ \\
\hline Interested in education ${ }^{c}$ & 70.2 & 73.9 & 70.4 & 73.9 \\
\hline
\end{tabular}

a $p<0.05$, Fisher's exact used when cell size $<5$

${ }^{b}$ Percent shown is percent of respondents who reported each reason as a notable barrier to asking patients about firearms

" Percent shown is percent of respondents who reported being "moderately," "very," or "extremely interested"

at risk for firearm injury (49.2\%), and not knowing how to ask (48.6\%) (Fig. 1). Psychiatry respondents reported notable barriers least often when compared with other specialties: $75 \%$ of psychiatry respondents reported insufficient time as the only notable barrier.

Respondents with lifetime exposure to firearms were less concerned about the legality of asking and less afraid of offending patients compared to those without exposure to firearms. Those with lifetime exposure to firearms more often did not ask because they did not think the topic was clinically relevant. Respondents with and without lifetime exposure were similar in reporting as notable barriers not knowing how to identify risk for firearm injury, not knowing how to ask, and not knowing what to do with the answers.

It might be worth noting that very few respondents in fact thought it might be illegal; this seems like it could be a generational difference between residents/ fellows and older trained physicians. Respondents who had received education less often believed that firearms are not within their scope of practice, and less frequently cited as barriers not knowing how to ask about firearms in the home
Table 3 Respondent experience and interest in clinical strategies for firearm injury prevention

\begin{tabular}{|c|c|c|c|c|}
\hline & Percent & Odds ratio & $95 \% \mathrm{Cl}$ & $P$ value \\
\hline \multicolumn{5}{|c|}{ Ever ask about firearm access ${ }^{\mathrm{a}}$} \\
\hline Primary Care & 45.2 & ref & - & - \\
\hline Surgery & 24.2 & 0.39 & $0.16-0.94$ & 0.036 \\
\hline Emergency & 54.2 & 1.43 & $0.59-3.49$ & 0.428 \\
\hline Psychiatry & 90.0 & 10.92 & $2.41-49.46$ & 0.002 \\
\hline Other & 4.2 & 0.05 & $0.01-0.41$ & 0.005 \\
\hline
\end{tabular}

Had firearm injury prevention in medical education

$\begin{array}{lllll}\text { Primary care } & 62.5 & \text { ref } & - & - \\ \text { Surgery } & 51.5 & 0.26 & 0.29-1.40 & 0.264 \\ \text { Emergency } & 79.2 & 1.24 & 0.79-6.59 & 0.128 \\ \text { Psychiatry } & 75.0 & 1.00 & 0.61-5.34 & 0.289 \\ \text { Other } & 33.3 & 0.14 & 0.12-0.77 & 0.012 \\ \text { nterested in firearm injury } & \text { prevention education } & & \\ \text { Primary care } & 77.9 & \text { ref } & - & - \\ \text { Surgery } & 54.6 & 0.34 & 0.15-0.78 & 0.011 \\ \text { Emergency } & 79.2 & 1.08 & 0.36-3.20 & 0.89 \\ \text { Psychiatry } & 85.0 & 1.61 & 0.43-5.97 & 0.48 \\ \text { Other } & 58.3 & 0.40 & 0.16-1.01 & 0.053\end{array}$

a Odds ratios compared ever asking with never asking

b Odds ratios compare being "moderately, "very," or "extremely" interested in firearm injury prevention education with being "not" or "slightly" interested

and not knowing what to do with the answers patients gave about access to firearms.

Respondents were interested in education on addressing firearms with patients regardless of their prior training on firearm injury prevention. More than $90 \%$ were somewhat or very interested in an educational program designed to increase knowledge and skills in counseling patients in strategies for reducing risk of firearm injury. Specifically, $81.7 \%$ of respondents reported interest in evidence-based interventions to decrease firearm injury and death in their patients, $54.5 \%$ were interested in legal mechanisms to separate dangerous people from their firearms, and $48.8 \%$ were interested in what questions to ask at-risk patients about their access to firearms.

\section{Discussion}

In light of increasing public health concern regarding firearm injury and death and a relative paucity of standard medical educational about firearms, this study examined the educational experience and behaviors related to risk of firearm access for patients and counseling when indicated among graduate medical trainees at a major academic medical center. Our findings suggest trainees endorse the clinician's role in identifying patients at risk for firearm-related harm and, when clinically relevant, discussing strategies to reduce that risk and have broad 


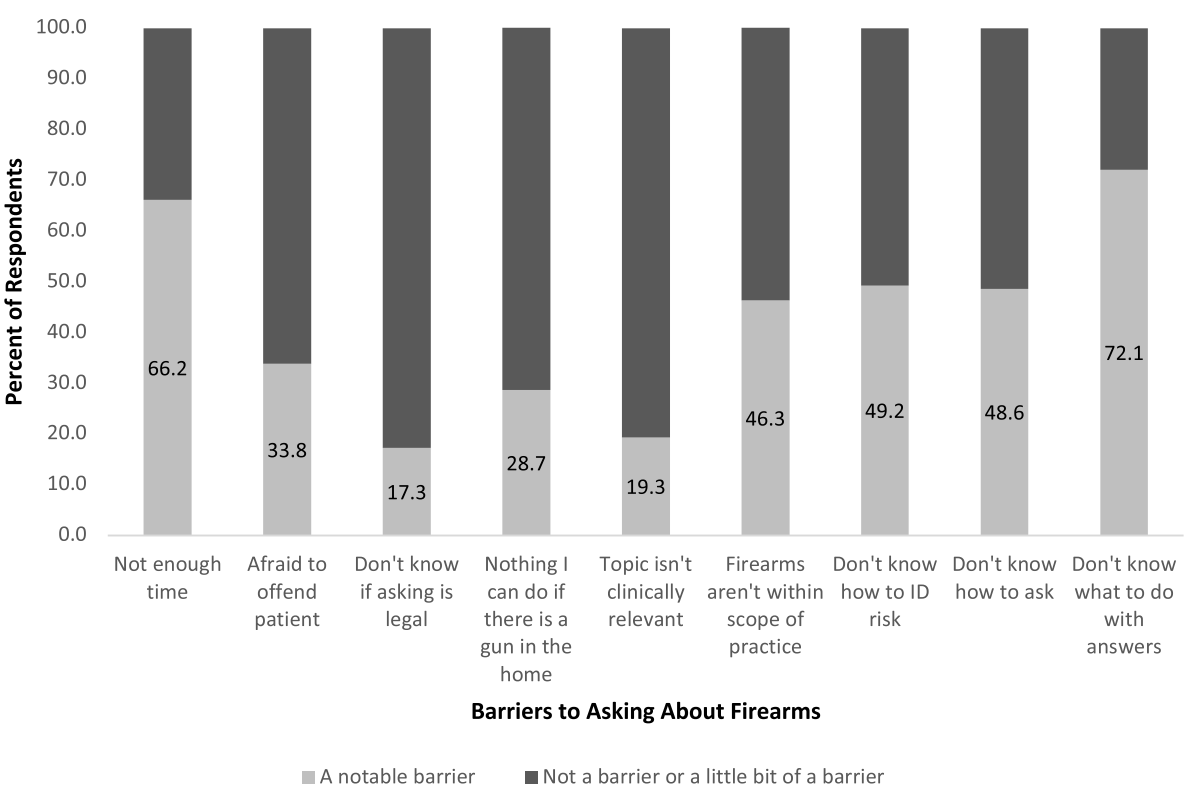

Fig. 1 Percent of respondents reporting notable barriers to asking about firearms. Survey data from residents and fellows at a large, urban, university-based academic medical center in $2018(n=218)$

interest in education on clinical strategies for preventing firearm-related harm. The results also shed light on a range of barriers, including time constraints and lack of knowledge of what to do when an at-risk patient has access to a firearm.

Respondents who had prior firearm education in medical training reported fewer barriers to addressing the topic in practice and a greater comfort in counseling asking than those who did not have firearm education in medical training. This suggests that medical education about firearms is effective in achieving its objective and might be a substantial driver of physician comfort and empowerment to raise this topic with patients. Variations between specialties were noted in several areas, including the frequency with which firearms were discussed and trainees' primary concerns regarding firearms. In addition to general training at the level of medical school, specialty-specific medical education for trainees may be useful in addressing potential specialty-specific concerns. For example, psychiatrists are overwhelmingly more concerned about suicide compared with those in other specialties; this is appropriate, given the high-risk nature of their patient population. Training on firearm injury prevention for psychiatrists, and others who see patients at risk of suicide, could include information on assessing risk for suicide and understanding the importance of lethal means access for suicidal persons. Lethal means counseling-talking with patients to remove access to firearms, medications, and other lethal means of suicide-is a promising and increasingly prioritized component of suicide prevention [26-28]. Trainees who see patients at risk of suicide should be educated on the potential of temporary transfer of firearms, a common method of reducing lethal means, to lessen suicide risk [29].

Surgeons reported a primary concern for homicide; they see relatively few patients with life-threatening selfinflicted firearm injuries (most deaths from such injuries are at the shooting scene) [30]. Surgeons could be trained in reducing recurrent interpersonal injury, as risk for firearm injury is increased among those who have experienced firearm injury in the past [31,32]. At some institutions, hospital-based violence intervention programs (HVIPs) support violently injured patients with comprehensive care that addresses both risk for future involvement in violence and psychological trauma, and provides social support to those who are recovering from violent injury [33].

Limited research and expert recommendations suggest that clinicians and trainees become educated on a harm reduction approach to firearm injury prevention, reasons for firearm ownership, the various safe firearm storage devices, firearms themselves, skills for having clinically relevant and collaborative conversations about the risks and benefits of firearms in the home, and strategies to keeping firearms out of the hands of those who are at risk [11, 13, 34-37]. Such conversations should include establishing a context of risk, focusing on reducing access to firearms for at-risk persons, and tailoring to 
the individual patient and storage or other risk reduction strategies that work for them.

A structured and standardized curriculum for trainees has the potential to decrease barriers to counseling, improve the practice of identifying risk for firearm-related harm, increase provider comfort with discussing the risks of access to firearms when appropriate, and knowing how to respond when an at-risk patients has firearm access. Currently, resources are available to assist in curriculum development and facilitate screening and counseling efforts. Several published articles [12, 13, 38] provide background information and specific recommendations. Other tools provide comprehensive online resources for learning about clinical strategies for preventing firearm-related harm, and make available tools for educators seeking to implement firearm injury prevention education in their curricula for medical and mental health clinicians and trainees $[39,40]$.

Our results should be interpreted with consideration of certain limitations. This study was a small, explorative survey done at a single academic medical center in California. Though we feel the responses generated are representative of the sentiments and behaviors of trainees at this institution, we are uncertain as to their generalizability to other institutions of medical training and other geographic settings. However, given the diversity of training backgrounds and medical specialties, we think this is an important contribution to the education science of firearm safety. The generalizability of our results may be further limited by the fact that our university has a dedicated firearm violence research center and, as a result, firearm injury prevention may be included in clinical education more often than at other institutions.

As with all survey research, our results are subject to nonresponse bias. Our survey had a response rate of $29 \%$, and we believe this is due in part to our inability to incentivize survey participation. Non-respondents may be different than those who chose to participate and we do not have any data on non-respondents. As this was a small quality improvement survey for one institution, the survey instrument was not evaluated for validity or reliability prior to distribution.

\section{Conclusions}

Clinicians occupy a unique position to identify increased risk for firearm-related harm and, when clinically indicated, to work with patients to reduce that risk. Many medical trainees, however, feel that their training inadequately addresses this topic and would like more education. Specialty, personal exposure to firearms, and previous education on the topic affected to what degree trainees discussed firearms with their patients, as well as their educational interests. Specialty-specific curricula that addresses specific concerns and barriers may be appropriate for residents and fellows.

\section{Supplementary Information}

The online version contains supplementary material available at https://doi. org/10.1186/s12909-021-03024-9.

Additional file 1. The complete survey instrument.

Additional file 2. Definition of collapsed variable categories.

Acknowledgements

Not applicable.

Authors' contributions

RP, ST, AA, GJW, AB conceptualized the project, developed the survey instrument, and collected the survey data. RP conducted all analyses and RP, ST, AA, GJW, $A B$, SS interpreted the analyses. RP, ST, AA, AB, SS drafted the work and RP, $S T, A A, A B, S S, R A S$, and GJW made critical revisions for important intellectual content. All authors approve of the final submitted paper and agree to be accountable for all aspects of the work.

\section{Funding}

Funding for this study comes from the University of California Firearm Violence Research Center with funds from the State of California, the California Wellness Foundation (Award Number: 2014-255), and the Heising-Simons Foundation (Award Number: 2017-0447).

Availability of data and materials

The datasets used and/or analysed during the current study are available from the corresponding author on reasonable request.

\section{Declarations}

\section{Ethics approval and consent to participate}

The study was deemed to not constitute research by the University of California at Davis Institutional Review Board and therefore ethics approval was waived. Informed consent was obtained from all study participants.

Consent for publication

Not applicable.

\section{Competing interests}

The authors declare that they have no competing interests.

\section{Author details}

${ }^{1}$ Violence Prevention Research Program, Department of Emergency Medicine, University of California Davis School of Medicine, 2315 Stockton Blvd, Sacramento, CA 95819, USA. ${ }^{2}$ University of California Firearm Violence Research Center at UC Davis, 2315 Stockton Blvd, Sacramento, CA 95819, USA. ${ }^{3}$ Department of Emergency Medicine, University of California, Davis, 2315 Stockton Blvd, Sacramento, CA 95817, USA. ${ }^{4}$ Department of Internal Medicine, University of California, Davis, 2315 Stockton Blvd, Sacramento, CA 95819, USA. ${ }^{5}$ Department of Family and Community Medicine, University of California, Davis, 2315 Stockton Blvd, Sacramento, CA 95819, USA. ${ }^{6}$ Department of General Surgery, Brigham and Women's Hospital, 75 Francis Street, Carrie Hall 103, Boston, MA 02115, USA. ${ }^{7}$ Department of Psychiatry and Behavioral Sciences, University of California, Davis, 2315 Stockton Blvd, Sacramento, CA 95819, USA.

Received: 30 March 2021 Accepted: 7 October 2021

Published online: 03 January 2022

\section{References}

1. Centers for Disease Control and Prevention. Injury prevention \& control: data \& statistics (WISQARS). www.cdc.gov/injury/wisqars/index.html. Accessed 24 Mar 2021.

2. Azrael D, Hepburn L, Hemenway D, Miller M. The stock and flow of U.S. firearms: results from the 2015 national firearms survey. RSF. 2017(3):3857. https://doi.org/10.7758/rsf.2017.3.5.02. 
3. Crifasi CK, Doucette ML, McGinty EE, Webster DW, Barry CL. Storage practices of US gun owners in 2016. Am J Public Health. 2018;108:532-7. https://doi.org/10.2105/AJPH.2017.304262.

4. Anglemyer A, Horvath T, Rutherford G. The accessibility of firearms and risk for suicide and homicide victimization among household members: a systematic review and meta-analysis. Ann Intern Med. 2014;160:101-10. https://doi.org/10.7326/M13-1301.

5. Brent DA, Perper JA, Allman CJ, Moritz GM, Wartella ME, Zelenak JP. The presence and accessibility of firearms in the homes of adolescent suicides. A case-control study. JAMA. 1991;266:2989-95.

6. Conwell Y, Duberstein PR, Connor K, Eberly S, Cox C, Caine ED. Access to firearms and risk for suicide in middle-aged and older adults. Am J Geriatr Psychiatry. 2002;10:407-16.

7. Grossman DC, Mueller BA, Riedy C, Dowd MD, Villaveces A, Prodzinski J, et al. Gun storage practices and risk of youth suicide and unintentional firearm injuries. JAMA. 2005;293:707-14. https://doi.org/10.1001/jama.293.6.707.

8. Kellermann AL, Rivara FP, Somes G, Reay DT, Francisco J, Banton JG, et al. Suicide in the home in relation to gun ownership. N Engl J Med. 1992;327:467-72. https://doi.org/10.1056/NEJM199208133270705.

9. Wiebe DJ. Homicide and suicide risks associated with firearms in the home: a national case-control study. Ann Emerg Med. 2003;41:771-82. https://doi.org/10.1067/mem.2003.187.

10. Studdert DM, Zhang Y, Swanson SA, Prince L, Rodden JA, Holsinger EE, et al. Handgun ownership and suicide in California. N Engl J Med. 2020;382:2220-9. https://doi.org/10.1056/NEJMsa1916744.

11. Pallin R, Spitzer SA, Ranney ML, Betz ME, Wintemute GJ. Preventing firearm-related death and injury. Ann Intern Med. 2019;170:ITC81-96. https://doi.org/10.7326/AITC201906040.

12. Roszko PJ, Ameli J, Carter PM, Cunningham RM, Ranney ML. Clinician attitudes, screening practices, and interventions to reduce firearm-related injury. Epidemiol Rev. 2015;38:87-110. https://doi.org/10.1093/epirev/mxv005.

13. Wintemute GJ, Betz ME, Ranney ML. Yes, you can: physicians, patients, and firearms. Ann Intern Med. 2016;165:205-13. https://doi.org/10.7326/M15-2905.

14. Betz ME, Miller M, Barber C, Beaty B, Miller I, Camargo CA Jr, et al. Lethal means access and assessment among suicidal emergency department patients. Depress Anxiety. 2016;33:502-11. https://doi.org/10.1002/da. 22486.

15. Price JH, Kinnison A, Dake JA, Thompson AJ, Price JA. Psychiatrists' practices and perceptions regarding anticipatory guidance on firearms. Am J Prev Med. 2007;33:370-3. https://doi.org/10.1016/j.amepre.2007.07.021.

16. Grossman DC, Mang K, Rivara FP. Firearm injury prevention counseling by pediatricians and family physicians. Practices and beliefs. Arch Pediatr Adolesc Med. 1995;149:973-7. https://doi.org/10.1001/archpedi.1995. 02170220039005

17. Butkus R, Doherty R, Bornstein SS, Carney JK, Cooney T, Engel L, et al. Reducing firearm injuries and deaths in the United States: a position paper from the American College of Physicians. Ann Intern Med. 2018;169:704-7. https://doi.org/10.7326/M18-1530

18. Firearm violence. California Medical Association. Accessed 30 July 2021. https://www.cmadocs.org/firearm-violence

19. Dowd MD, Sege RD, Gardner HG, Quinlan KP, Ewald MB, Ebel BE, et al. Firearm-related injuries affecting the pediatric population. Pediatrics. 2012:130(5):e1416-23. https://doi.org/10.1542/peds.2012-2481.

20. Damari ND, Ahluwalia KS, Viera AJ, Goldstein AO. Continuing medical education and firearm violence counseling. AMA J Ethics. 2018;20:56-68. https://doi.org/10.1001/journalofethics.2018.20.1.stas1-1801.

21. Puttagunta R, Coverdale TR, Coverdale J. What is taught on firearm safety in undergraduate, graduate, and continuing medical education? A review of educational programs. Acad Psychiatry. 2016;40:821-4. https://doi.org/ 10.1007/s40596-016-0490-6.

22. Coverdale $\mathrm{JH}$, Roberts LW, Balon R. The public health priority to address the accessibility and safety of firearms: recommendations for training. Acad Psychiatry. 2010;34:405-8. https://doi.org/10.1176/appi.ap.34.6.405.

23. Price JH, Thompson AJ, Khubchandani J, Mrdjenovich AJ, Price JA. Firearm anticipatory guidance training in psychiatric residency programs. Acad Psychiatry. 2010:34:417-23. https://doi.org/10.1176/appi.ap.34.6.417.

24. Price JH, Bedell AW, Everett SA, Oden L. Training in firearm safety counseling in family practice residency programs. J Community Health 1997;22:91-9. https://doi.org/10.1023/a:1025108721292.
25. Price $\mathrm{JH}$, Conley PM, Oden L. Training in firearm safety counseling in pediatric residency programs. Arch Pediatr Adolesc Med. 1997;151:306-10. https://doi.org/10.1001/archpedi.1997.02170400092016.

26. Office of the U.S. Surgeon General \& Action Alliance. The U.S. Department of Health and Human Services. 2012 National Strategy for Suicide Prevention: Goals and Objectives for Action. 2012. https://www.hhs.gov/ sites/default/files/national-strategy-for-suicide-prevention-overview.pdf. Accessed 30 July 2021.

27. The Harvard Injury Control Research Center. Means Matter. https://www. hsph.harvard.edu/means-matter/. Accessed 30 July 2021.

28. Mann JJ, Michel CA. Prevention of firearm suicide in the United States: what works and what is possible. Am J Psychiatry. 2016;173:969-79. https://doi.org/10.1176/appi.ajp.2016.16010069.

29. McCourt AD, Vernick JS, Betz ME, Brandspigel S, Runyan CW. Temporary transfer of firearms from the home to prevent suicide: legal obstacles and recommendations. JAMA Intern Med. 2017;177:96-101. https://doi.org/ 10.1001/jamainternmed.2016.5704.

30. Kellermann AL, Rivara FP, Lee RK, Banton JG, Cummings P, Hackman BB, et al. Injuries due to firearms in three cities. N Engl J Med. 1996;335:143844. https://doi.org/10.1056/NEJM199611073351906.

31. Rowhani-Rahbar A, Zatzick D, Wang J, Mills BM, Simonetti JA, Fan MD, et al. Firearm-related hospitalization and risk for subsequent violent injury, death, or crime perpetration: a cohort study. Ann Intern Med. 2015;162:492-500. https://doi.org/10.7326/M14-2362.

32. Pear VA, McCort CD, Kravitz-Wirtz N, Shev AB, Rowhani-Rahbar A, Wintemute GJ. Risk factors for assaultive reinjury and death following a nonfatal firearm assault injury: a population-based retrospective cohort study. Prev Med. 2020;139:106198. https://doi.org/10.1016/j.ypmed.2020. 106198.

33. Juillard C, Cooperman L, Allen I, Pirracchio R, Henderson T, Marquez R, et al. A decade of hospital-based violence intervention: benefits and shortcomings. J Trauma Acute Care Surg. 2016;81:1156-61. https://doi. org/10.1097/TA.0000000000001261.

34. Pallin R, Siry B, Azrael D, Knoepke CE, Matlock DD, Clement A, et al. "Hey, let me hold your guns for a while": a qualitative study of messaging for firearm suicide prevention. Behav Sci Law. 2019;37:259-69. https://doi. org/10.1002/bsl.2393.

35. Betz ME, Wintemute GJ. Physician counseling on firearm safety: a new kind of cultural competence. JAMA. 2015;314:449-50. https://doi.org/10. 1001/jama.2015.7055.

36. Olson LM, Christoffel KK, O'Connor KG. Pediatricians' involvement in gun injury prevention. Inj Prev. 2007;13:99-104. https://doi.org/10.1136/ip. 2006.012401.

37. Barber C, Frank E, Demicco R. Reducing suicides through partnerships between health professionals and gun owner groups-beyond Docs vs Glocks. JAMA Intern Med. 2017;177:5-6. https://doi.org/10.1001/jamai nternmed.2016.6712.

38. Rowhani-Rahbar A, Simonetti JA, Rivara FP. Effectiveness of interventions to promote safe firearm storage. Epidemiol Rev. 2016;38:111-24. https:// doi.org/10.1093/epirev/mxv006.

39. The BulletPoints Project. https://www.bulletpointsproject.org. Accessed 24 Mar 2021

40. Hoops K, Fahimi J, Khoeur L, Studenmund C, Barber C, Barnhorst A, et al. Consensus-Driven Priorities for Firearm Injury Education Among Medical Professionals. Acad Med. 2021. https://doi.org/10.1097/ACM.0000000000 004226.

\section{Publisher's Note}

Springer Nature remains neutral with regard to jurisdictional claims in published maps and institutional affiliations. 